\title{
Galactorrhea Probably Related with Switching from Osmotic-release Oral System Methylphenidate (MPH) to Modified-release MPH: An Adolescent Case
}

\author{
Ozalp Ekinci, Serkan Gunes, Nuran Ekinci \\ Department of Child and Adolescent Psychiatry, Mersin University School of Medicine, Mersin, Turkey
}

Galactorrhea, as an adverse effect of psychotropic medications, usually develops due to high dose of antipsychotics. Selective serotonin reuptake inhibitors (SSRIS) have also been reported to be related to galactorrhea. To the best of our knowledge, no previous study reported galactorrhea with methylphenidate (MPH) use. Hereby, we report a case of an adolescent girl who developed galactorrhea after increasing his modifed-release oral MPH to $50 \mathrm{mg} /$ day while under treatment of sertraline and very low dose haloperidol.

KEY WORDS: Galactorrhea; Methylphenidate; Selective serotonin reuptake inhibitors; Adolescent.

\section{INTRODUCTION}

Endocrine adverse effects are very rare with methylphenidate (MPH) use. In the literature, only three case reports are available which reported gynecomastia in subjects who were treated with MPH for attention-deficit/hyperactivity disorder (ADHD). ${ }^{1-3)}$ Galactorrhea, as an adverse effects of psychotropic medications, usually develops due to high dose of antipsychotics. Selective serotonin reuptake inhibitors (SSRIs) have also been reported to be related to galactorrhea. ${ }^{4)}$ To the best of our knowledge, no previous study reported galactorrhea with MPH use. Hereby, we report a case of a adolescent girl who developed galactorrhea after increasing his modifed-release oral MPH from 40 to $50 \mathrm{mg}$ /day while under treatment of sertraline and very low dose haloperidol.

\section{CASE}

A 15-year-old girl was diagnosed with adjustment disorder with depressive symptoms and trichotillomania. Family reported that the presenting symptoms have emerged after a perantal relationship problem. Her psy-

\footnotetext{
Received: April 1, 2016 / Revised: May 6, 2016

Accepted: June 6, 2016

Address for correspondence: Ozalp Ekinci, MD

Department of Child and Adolescent Psychiatry, Mersin University School of Medicine, Mersin, Turkey

Tel: +90-506-611-15-00, Fax: +90-324-241-00-92

E-mail: ozalpekinci@yahoo.com
}

chiatric history revealed that she had been diagnosed with ADHD combined type when she was 9 years old and she was on osmotic-release oral system (OROS) MPH 54 $\mathrm{mg}$ /day for 2 years. She had a Children's Depression Inventory (CDI) total score of 24 at admission. Her body weight was $62 \mathrm{~kg}$. To target the depressive and trichotillomania symptoms, sertraline was firstly initiated in the dose of $50 \mathrm{mg} / \mathrm{day}$, and was gradually increased to 100 $\mathrm{mg} /$ day. Depressive symptoms greatly resolved however, tricotillomania was largely unchanged. As an addition to the sertraline treatment, risperidone $1 \mathrm{mg} / \mathrm{day}$ was inititated. After 2 weeks, since risperidone induced increased appettite, risperidone was switched to haloperidol in the dose of $0.5 \mathrm{mg} /$ day ( 5 drops). Haloperidol was used nightly since trichotillomania was evident only in the night time. During these treatments, OROS MPH treatment was kept unchanged. After 8 weeks of sertraline and haloperidol treatment, tricotillomania symptoms also greatly reduced. At the 12-week-follow-up, family reported that the patient had significant inattentiveness symptoms at school, especially in the early hours. OROS MPH was firstly increased to $72 \mathrm{mg}$ /day; however, the patient could not tolerate this dose due to severe head ache. Thereafter, OROS MPH was switched to MPH-modifed release, beginning with the dose of $30 \mathrm{mg} /$ day. Patient tolerated the initial doses well and, in 2 weeks, MPH dose was planned to increase to $50 \mathrm{mg} /$ day. Three days after MPH was increased to $50 \mathrm{mg} /$ day, family communicated that the patient had spontaneous flow of milk from both of

(a) This is an Open-Access article distributed under the terms of the Creative Commons Attribution Non-Commercial License (http://creativecommons.org/licenses/by-nc/4.0) which permits unrestricted non-commercial use, distribution, and reproduction in any medium, provided the original work is properly cited. 
her breasts. For the evaluation of galactorrhea, the patient was consulted to obstetrics and pediatric endoncrinology clinics. Her physical examination and laboratory workup including liver, thyroid, and renal function tests; electrolytes; blood cell count; testosterone; estrogen; luteinizing hormone; follicle-stimulating hormone; and cortisol levels were all within normal range, while her prolactin level was found as $67.7 \mathrm{ng} / \mathrm{ml}$ (normal value, 6-29.9 ng/ml). No medical or surgical condition was detected to explain the galactorrhea. The evaluation of the Naranjo adverse drug reaction (ADR) probability scale was 7 (which indicates a probable ADR). Due to the suspect of an ADR, modified-release $\mathrm{MPH}$ and haleperidole was discontinued while continuing sertraline in the dose of $50 \mathrm{mg} /$ day. One week later, galactorrhea symptoms resolved completely. Fifteen days after discontinuation, prolactin level of the patient was found as $19.4 \mathrm{ng} / \mathrm{ml}$.

\section{DISCUSSION}

In the present case, all of the three psychotropic agents may be related with development of galactorrhea, while haloperidol is a widely known cause of medication-induced galactorrhea. ${ }^{5)}$ Haloperidol, which is a potent dopamine receptor antagonist, may be considered a potential candidate to cause hyperprolactinemic galactorrhea. However, the 3-month use of very low dose haleperidol may unlikely cause hyperprolactinemia symptoms in an adolescent. The concomitant use of sertraline may also be related with the adverse reaction. SSRIs have been previously linked with normoprolactinemic and hyperprolactinemic galactorrhea. ${ }^{4,6)}$ Galactorrhea has been reported to develop either acutely or months after the initiation of SSRIs. ${ }^{4)}$ In the available literature, three adult case reports exist for sertraline-induced galactorrhea. ${ }^{4,7,8)}$ It has been suggested that the inhibition of dopaminergic neurotransmission by SSRIs can be related to adverse effects such as hyperprolactinemia. ${ }^{9)}$ There is also evidence from animal studies that sertraline may increase extracellular dopamine levels in the nucleus accumbens and striatum. $^{10)}$

It should be noted that our case developed galactorrhea shortly after the switching from OROS MPH to modified-release MPH. Therefore, this switching might have increased the vulnerabilty of the patient to extrapyramidal symptoms. The exact pathophysiological mechanisms through which the switching of MPH can cause galactorrhea are unknown. Alhough not previously shown, the differential effects of OROS MPH and modified-release
MPH on dopaminergic activation may be a candidate mechanism. Equivalent daily doses modified-release MPH and OROS MPH have been shown to result in different levels of action throughout the day. Modified-release MPH may be considered to have almost twice as higher dopaminergic activity then OROS MPH (50\% vs. $22 \%$ ) in the first hours of treatment. ${ }^{11)}$ In our case, the high dose of modified-release MPH, especially in a more stricted duration, may have resulted in an overdopaminergic state. One explanation may be that the higher dopaminergic concentration with modified-release MPH may have led to a higher degree of dopaminergic blockade by haloperidol. In an earlier case report, it has been postulated that the dopamine-blocking actions of typical antipsychotics may necessitate the use of larger quantities of stimulants. ${ }^{12)}$ In the present case, the higher availability of dopamine by modifed-release MPH may have potentiated the dopaminergic blockade of haloperidol and, in turn, may have resulted in galactorrhea.

Galactorrhea can be related with numerous drugs including antidepressants, antipsychotics, anxiolytics, antihypertensives, antihistamines, antiepileptics and hormones. ${ }^{13)}$ In the comprehensive review by Peña and Rosenfeld, ${ }^{13)}$ amphetamines have also been mentioned among the medications that cause galactorrhea. Since amphetamines are a class of potent dopamine and noradrenaline reuptake blockers, ${ }^{14)}$ it can be postulated that monoamine reuptake blockade may be a rare mechanism of medication-induced galactorrhea. In line with this assumption, serotonin norepinephrine reuptake inhibitor (SNRI) group antidepressants have been reported to cause galactorrhea. ${ }^{15)}$ Although MPH's main mechanism of action is the inhibition of dopamine reuptake, it also has an affinity on noradrenaline transporter. ${ }^{16)}$ To the best of our knowledge, the present report is the first to link MPH use with galactorrhea.

Serotonin may have an important role in regulating human prolactin. ${ }^{13)}$ In the present case, serotonergic activation may also be responsible for the development of galactorrhea. The effects of MPH on serotonin system is largely unknown. However, some animal studies have shown that MPH may act on serotonergic receptors and increase serotonin levels. ${ }^{17,18)}$ In the present case, the serotonergic activity of sertraline may be potentiated by high dose MPH and galactorrhea may have developed through this mechanism.

In the present case, before the resolution of galactorrhea, the patient was discontinued from both MPH and haloperidol. Therefore, it is difficult to arrive a clear conclusion about the real cause of galactorrhea. Clinicians 
should be aware of rare adverse effects when using polypharmacy in children and adolescents, especially when antipsychotics are present in the medication regimen. Given the high risk of extrapyramidal adverse effects in youth, extra caution must be given when changing the medication regimens. The possible drug-interactions and receptor regulations may be related with rare adverse reactions including galactorrhea. Concomitant use of medications that are reported to be associated with galactorrhea may increase the likelihood of this adverse reaction.

\section{REFERENCES}

1. Ensat F, Edelbauer M, Wechselberger G. Unilateral gynecomastia in a prepubertal boy. Eur J Pediatr 2012;171:197.

2. Coskun M, Adak I, Akaltun I. Bilateral gynecomastia in a preadolescent boy while under treatment with methylphenidate and paroxetine. J Clin Psychopharmacol 2014;34: 537-538.

3. Almıs BH, Almıs H, Celik M, Gümüstaș F, Turgut M. Methylphenidate induced gynecomastia in a prepubertal boy: a case report. Anadolu Psikiyatri Derg 2016;17(Suppl 3): 74-76.

4. Nebhinani N. Sertraline-induced galactorrhea: case report and review of cases reported with other SSRIs. Gen Hosp Psychiatry 2013;35:576.e3-5.

5. Windgassen K, Wesselmann U, Schulze Mönking H. Galactorrhea and hyperprolactinemia in schizophrenic patients on neuroleptics: frequency and etiology. Neuropsychobiology 1996;33:142-6.

6. Chatterjee SS, Mitra S, Mallik N. Emerging hyperprolactinemic galactorrhea in obsessive compulsive disorder with a stable dose of fluoxetine. Clin Psychopharmacol Neurosci 2015;13:316-8

7. Bronzo MR, Stahl SM. Galactorrhea induced by sertraline. Am J Psychiatry 1993;150:1269-1270.
8. Lesaca TG. Sertraline and galactorrhea. J Clin Psychopharmacol 1996;16:333-334.

9. Damsa C, Bumb A, Bianchi-Demicheli F, Vidailhet P, Sterck R, Andreoli A, et al. "Dopamine-dependent" side effects of selective serotonin reuptake inhibitors: a clinical review. J Clin Psychiatry 2004;65:1064-1068.

10. Kitaichi Y, Inoue T, Nakagawa S, Boku S, Kakuta A, Izumi $\mathrm{T}$, et al. Sertraline increases extracellular levels not only of serotonin, but also of dopamine in the nucleus accumbens and striatum of rats. Eur J Pharmacol 2010;647:90-96.

11. Coghill D, Banaschewski T, Zuddas A, Pelaz A, Gagliano A, Doepfner M. Long-acting methylphenidate formulations in the treatment of attention-deficit/hyperactivity disorder: a systematic review of head-to-head studies. BMC Psychiatry 2013;13:237.

12. Husain A, Chapel J, Malek-Ahmadi P. Methylphenidate, neuroleptics and dyskinesia-dystonia. Can $J$ Psychiatry 1980;25:254-258

13. Peña KS, Rosenfeld JA. Evaluation and treatment of galactorrhea. Am Fam Physician 2001;63:1763-1770.

14. Sulzer D, Sonders MS, Poulsen NW, Galli A. Mechanisms of neurotransmitter release by amphetamines: a review. Prog Neurobiol 2005;75:406-433.

15. Ashton AK, Longdon MC. Hyperprolactinemia and galactorrhea induced by serotonin and norepinephrine reuptake inhibiting antidepressants. Am J Psychiatry 2007;164:11211122.

16. Hannestad J, Gallezot JD, Planeta-Wilson B, Lin SF, Williams WA, van Dyck $\mathrm{CH}$, et al. Clinically relevant doses of methylphenidate significantly occupy norepinephrine transporters in humans in vivo. Biol Psychiatry 2010;68: 854-860.

17. Volkow ND, Gatley SJ, Fowler JS, Wang GJ, Swanson J. Serotonin and the therapeutic effects of ritalin. Science 2000;288:11.

18. Daniali S, Nahavandi A, Madjd Z, Shahbazi A, Niknazar S, Shahbazzadeh D. Chronic Ritalin administration during adulthood increases serotonin pool in rat medial frontal cortex. Iran Biomed J 2013;17:134-139. 